\title{
Total Factor Productivity and China's Outward FDI: Based on a Firm-Level Empirical Investigation
}

\author{
Xiaoxue Du ${ }^{\mathrm{a}}$, Juanli Lan ${ }^{\mathrm{b}}$, Nisha $\mathrm{Jia}^{\mathrm{c}}$ and Chao Liu ${ }^{\mathrm{d}}$ \\ International Business School, Shaanxi Normal University, Xi' an 710119, China

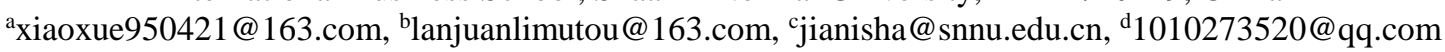

\begin{abstract}
Since the reform and opening up, China's economy has achieved continuous development and an increasing flow of foreign direct investment. This study focuses on the impact of enterprises' total factor productivity on the outward foreign direct investment of companies at a micro level. The data comes from Chinese manufacturing companies from 2005 to 2007. We use a Probit model to empirically test the impact of total factor productivity of Chinese manufacturing companies on their outward foreign direct investment decisions. The test results show the following evidence: firstly, the total factor productivity of an enterprise is an influencing factor of Chinese enterprises' outward direct foreign investment decisions; secondly, the higher the total factor productivity, the greater the probability of outward direct foreign investment.
\end{abstract}

Keywords-Enterprise heterogeneity; Outward Foreign Direct Investment; Total Factor Productivity; Probit Model

\section{INTRODUCTION}

Foreign direct investment (FDI) has created a lot of vitality for Chinese companies and eased the problem of insufficient capital in the early stages of China's economic transformation. The strategy of going global and the intense competition in the domestic market as well as the low average profit rate created new challenges. Nowadays, the number of outward foreign direct investment (OFDI) enterprises in China has continued to increase with the high growth rate and large flow. The total amount of China's OFDI is still behind the developed countries such as the United States, the European Union and Japan, although the growth rate is relatively fast. Thus, what are the factors influencing enterprises' OFDI? The core question of this paper is: How does the total factor productivity of an enterprise affect its OFDI decision, is it promoted or suppressed?

In the field of international investment, Hymer et al. first proposed the monopoly superiority theory to explore the issue of foreign investment of enterprises. Based on the traditional investment theory, Dunning proposed the eclectic theory of international production. After the 1980s, more and more scholars began to pay attention to the field of foreign investment in emerging market countries. Quite representative, Dunning and Narula combined the OIL paradigm with the stage of investment development. With the development of these theories, the OFDI of Chinese enterprises has been more reasonably explained.

In the economics literature, Melitz (2003) established a dynamic industrial model with heterogeneous firms and found that trade would induce more production firms to enter the export market, while at the same time forcing companies with the lowest productivity to withdraw. [1] Then, Helpman, Melitz, and Yeaple (2004) extended the heterogeneity of firms to OFDI, and found that firms with the highest productivity would choose OFDI while those with medium productivity would choose to export. Besides, firms with lower productivity serve the domestic market while the lowest productivity companies quit the market.[2] Chen Jinghua (2015) applied cutting-edge heterogeneity trade theory to the service industry and used industry panel data to find that industry productivity was an important factor affecting OFDI. [3] Tian Wei et al. (2012) used Zhejiang manufacturing company-level data and use the TFP measured by the OP method to reflect the company's productivity, finding that there was a positive relationship between productivity and the probability as well as the scale of OFDI. [4] Han Jian (2014) classified the types of OFDI into horizontal and vertical types during modeling. They found there was no "productivity paradox" in OFDI [5]. Although the above literature examines the relationship between OFDI and enterprise productivity through TFP in the discussion, it does not give a direct answer to the effect of TFP on OFDI. Therefore, the core of this paper's research is the influence of the total factor productivity of enterprises on their OFDI decisions.

Compared with the existing research literature, the contribution of this paper mainly lies in: (1) directly answering the question of the impact of TFP on OFDI; (2) examining the core issue from the micro enterprise level and eliminating the biased measurement problem caused by macro data.

\section{METHODOLOGY AND DATA}

\section{A. The Calculation of Total Factor Productivity}

In this paper, Levinsohn and Petrin (2003) method [6] is used to avoid the endogenous nature of traditional OLS method to calculate the TFP of enterprises. We use industrial added value instead of output to estimate TFP. The estimate is as follows:

$$
\mathrm{v}_{\mathrm{it}}=\beta_{1} l_{\mathrm{it}}+\phi_{\mathrm{t}}\left(k_{\mathrm{it}}+m_{\mathrm{it}}\right)+\eta_{\mathrm{it}}
$$

Where, $\phi_{t}\left(k_{i t}+m_{i t}\right)=\beta_{0}+\beta_{k} k_{i t}+\omega_{i t}$, the variables are in logarithmic form. $\mathrm{V}$ is the industrial added value, 1 is the labor force, $\mathrm{m}$ is the intermediate input, and $\mathrm{k}$ is the 
capital. $\phi_{t}\left(k_{i t}+m_{i t}\right)$ is a third-order polynomial approximation of $\mathrm{k}$ and $\mathrm{m}$.

We use formula (1) to estimate the coefficient of labor and capital, and then to obtain:

$$
\widehat{\mathrm{TFP}_{\mathrm{it}}}=\mathrm{V}_{\text {it }}-\widehat{\beta_{1}} l_{\text {it }}-\widehat{\beta_{k}} k_{\text {it }}
$$

\section{B. Data Sources and Samples}

The corporate data of this paper comes from the "List of Foreign Investment Enterprises (Organizations)" (hereinafter referred to as the "List") provided by the Ministry of Commerce website and "China Industrial Enterprise Database". Based on the literature of Nie Huihua et al., (2012), this paper first deals with the preliminary processing of the sample of the industrial enterprise database and eliminates companies that lack key financial indicators, employ less than 10 employees, and whose financial information does not meet accounting standards (GAAP). We matched the "List" with the database of industrial enterprises, and excluded the companies that did not have data in the previous period of OFDI, retaining the information on the first time of OFDI enterprises. Finally, we obtained 699 foreign investment companies. As the large-scale outward foreign direct investment of Chinese companies has been mainly since 2005 , the final data range selected for this paper is from 2005 to 2007 in order to more accurately reveal the relationship between total factor productivity and OFDI.

Table 1 is a preliminary statistical description of the company's main indicators. It divides the company into domestic, export, and outward investment companies. It then compares the key variables, such as the TFP, capital, labor, age, and number of firms $(\mathrm{N})$ of different types of companies, etc. It is not difficult to find that the average value of total factor productivity of foreign-invested enterprises is greater than that of export enterprises and local enterprises in any year, and the total factor productivity of export enterprises is greater than that of local enterprises. In addition, the average value of the employees, capital, age, and R\&D dummy variables of OFDI enterprises is higher than that of other two types of enterprises.

TABLE I COMPARISON OF THE MEAN VALUE OF VARIABLES AMONG DIFFERENT COMPANIES

\begin{tabular}{|c|c|c|c|c|c|c|c|c|c|}
\hline & \multicolumn{3}{|c|}{2005} & \multicolumn{3}{|c|}{2006} & \multicolumn{3}{|c|}{2007} \\
\hline & Local & Export & OFDI & Local & Export & OFDI & Local & Export & OFDI \\
\hline TFP & 6.443 & 6.681 & 7.300 & 6.598 & 6.828 & 7.386 & 6.728 & 6.898 & 7.717 \\
\hline labor & 4.690 & 5.356 & 5.941 & 4.705 & 5.386 & 6.009 & 4.733 & 5.423 & 6.076 \\
\hline capital & 8.016 & 8.694 & 9.611 & 8.089 & 8.793 & 9.628 & 8.128 & 8.867 & 9.972 \\
\hline age & 8.803 & 9.028 & 9.935 & 9.762 & 9.913 & 10.843 & 10.739 & 10.797 & 10.850 \\
\hline D_rd & 0.343 & 0.479 & 0.680 & 0.354 & 0.505 & 0.714 & 0.116 & .198 & 0.405 \\
\hline D_foreign & 0.062 & 0.255 & 0.203 & 0.060 & 0.255 & 0.190 & 0.059 & .263 & 0.195 \\
\hline D_con & 0.051 & 0.042 & 0.048 & 0.047 & 0.038 & 0.069 & 0.045 & .033 & 0.059 \\
\hline $\mathrm{N}$ & 87246 & 46234 & 231 & 87073 & 46418 & 248 & 88997 & 44489 & 220 \\
\hline
\end{tabular}

\section{EMPIRICAL RESULTS}

\section{A. Preliminary Measurement Results}

Based on the above analysis, we tentatively judged the differences between OFDI firms and non-OFDI firms in total factor productivity. Further, consider the following two regressions:

$$
\begin{aligned}
\operatorname{TFP}_{\text {it }}= & \alpha_{0}+\alpha_{1} D_{-} e x+X_{i}+\varepsilon_{i t} \\
& \operatorname{TFP}_{\text {it }}=\alpha_{0}+\alpha_{1} D_{-} \text {of } d i+X_{i t}+\varepsilon_{i t}
\end{aligned}
$$

Where, D_ofdi indicates whether foreign investment was made in the current year, D_ex indicates whether to export, and $\mathrm{Xi}$ indicates other control variables. In order to control the time effect, we make a preliminary return from the year to year.

The column (1) in Table 2 shows that after adding the control variable, the regression coefficient of the explanatory variable D_ex is negative, and it is significant at the statistical level of $10 \%$, which verifies the "paradox of productivity". The variable D_ofdi of the column (2) has a positive regression coefficient and is robust. This shows that compared with non-OFDI enterprises, OFDI companies have higher total factor productivity, which is in line with the preliminary judgment.

From the perspective of other control variables, the coefficients of labor and capital of companies are significantly positive, indicating that the more employees in the company and the more capital there is, the higher the total factor productivity is. The coefficient of firm age is significantly negative. This may be due to the fact that the management system of a long-established company is more limited and affects total factor productivity. Whether the company has a foreign investment coefficient is significant and positive, indicating that foreign-invested shares significantly increase the company's total factor productivity. And the coefficient of whether the company is state-owned is significantly negative, while foreign capital has an opposite effect. In a word, the total factor productivity of an enterprise is an important factor affecting the decision of an enterprise's OFDI decisions. 
TABLE II RESULTS OF REGRESSION TESTS

\begin{tabular}{|c|c|c|c|c|c|c|}
\hline & \multicolumn{3}{|c|}{ (1) } & \multicolumn{3}{|c|}{ (2) } \\
\hline & 2005 & 2006 & 2007 & 2005 & 2006 & 2007 \\
\hline \multirow[t]{2}{*}{ D_ex } & $-0.108 * * *$ & $-0.131 * * *$ & $-0.247 * * *$ & & & \\
\hline & $(-19.59)$ & $(-23.42)$ & $(-43.14)$ & & & \\
\hline \multirow[t]{2}{*}{ D_ofdi } & & & & $0.246 * * *$ & $0.179 * * *$ & $0.248 * * *$ \\
\hline & & & & $(4.22)$ & $(3.15)$ & $(4.04)$ \\
\hline \multirow[t]{2}{*}{ Labor } & $0.326 * * *$ & $0.330 * * *$ & $0.397 * * *$ & $0.312 * * *$ & $0.313 * * *$ & $0.366^{* * * *}$ \\
\hline & (114.17) & (114.62) & (135.27) & (112.48) & (111.93) & (127.70) \\
\hline \multirow[t]{2}{*}{ Lcap } & $0.165 * * *$ & $0.171 * * *$ & $0.134 * * *$ & $0.166^{* * *}$ & $0.172 * * *$ & $0.134 * * *$ \\
\hline & (86.98) & (89.74) & (71.29) & (87.14) & (89.85) & $(70.86)$ \\
\hline \multirow[t]{2}{*}{ age } & $-0.004 * * *$ & $-0.005 * * *$ & $-0.007 * * *$ & $-0.004 * * *$ & $-0.005 * * *$ & $-0.007 * * *$ \\
\hline & $(-13.73)$ & $(-19.43)$ & $(-26.87)$ & $(-13.27)$ & $(-18.85)$ & $(-25.68)$ \\
\hline \multirow[t]{2}{*}{ D_rd } & $-0.059 * * *$ & $-0.079 * * *$ & $0.255^{* * *}$ & $-0.065 * * *$ & $-0.087 * * *$ & $0.240 * * *$ \\
\hline & $(-11.20)$ & $(-14.89)$ & $(34.54)$ & $(-12.22)$ & $(-16.30)$ & $(32.25)$ \\
\hline \multirow[t]{2}{*}{ D_for } & $0.131 * * *$ & $0.139 * * *$ & $0.107 * * *$ & $0.095 * * *$ & $0.095^{* * *}$ & $0.019^{* *}$ \\
\hline & $(16.92)$ & $(17.82)$ & (13.39) & (12.62) & $(12.52)$ & $(2.46)$ \\
\hline \multirow[t]{2}{*}{ D_con } & $-0.038 * * *$ & $-0.069 * * *$ & $-0.123 * * *$ & $-0.024 * *$ & $-0.052 * * *$ & $-0.085 * * *$ \\
\hline & $(-3.15)$ & $(-5.56)$ & $(-9.44)$ & $(-1.97)$ & $(-4.16)$ & $(-6.52)$ \\
\hline \multirow[t]{2}{*}{ _cons } & $3.638 * * *$ & $3.737 * * *$ & $3.812 * * *$ & $3.668 * * *$ & $3.775^{* * *}$ & $3.887 * * *$ \\
\hline & $(255.95)$ & $(259.21)$ & $(261.38)$ & $(258.99)$ & $(262.79)$ & (266.38) \\
\hline $\mathrm{N}$ & 133541 & 133541 & 133541 & 133541 & 133541 & 133541 \\
\hline $\mathrm{r} 2 \_\mathrm{a}$ & 0.262 & 0.263 & 0.289 & 0.260 & 0.260 & 0.279 \\
\hline $\mathrm{F}$ & 771.675 & 6801.477 & 7764.343 & 6701.072 & 6697.521 & 7398.678 \\
\hline
\end{tabular}

Note: $* * *, * *$, and $*$ indicate significance levels of $1 \%, 5 \%$, and $10 \%$, respectively. Same as below.

$$
\begin{aligned}
& \operatorname{Pr}\left(D_{\text {ofdi it }}=1 \mid X_{\mathrm{it}}\right) \\
& \quad=\beta_{0}+\beta_{1} T F P_{\mathrm{it}}+\beta_{2} \text { lcapital }_{\mathrm{it}}+\beta_{3} \text { labor }_{\mathrm{it}}+\beta_{4} a g e_{\mathrm{it}}+\beta_{5} \mathrm{D}_{-} \mathrm{ex}_{\mathrm{it}}+\beta_{6} D_{-} \text {foreign }_{\mathrm{it}}
\end{aligned}
$$$$
+\beta_{7} D_{-} \operatorname{con}_{\text {it }}+\varepsilon_{\mathrm{it}}
$$

B. The Effect of Enterprise's Total Factor Productivity on Its Foreign Direct Investment Decision-making

In this section, we use the Probit probability model to estimate the decision-making behavior of enterprises.

From the column (1) in Table 3, it can be seen that without the control variable, the total factor productivity of the company has a significant positive impact on the company's foreign investment decision. At the same time, column (2) controls corporate capital, employees, age, etc. The result still shows that the higher the total factor productivity, the greater the probability OFDI. From the perspective of control variables, the company's capital, labor and export experience can all significantly increase the probability of an enterprise's OFDI. The firm's age coefficient is significantly negative, probably because the more difficult it is for a company to manage its age, the more difficult it is to adapt to a changing investment environment. Whether the foreign capital coefficient is significantly negative means that the increase in foreign capital will significantly reduce the probability of the company's decision of OFDI. The coefficient of whether the company is state-owned is not significant. Column (3) controls the time and industry effects, and the coefficient of each variable is still robust. 
Then, we control endogenousnes and remove the learning effect of FDI firms. Referring to Tian Wei et al., (2012), in columns (4) and (5), we use the value that lag the first-period of total factor performance for regression analysis. The enterprises with higher total factor productivity still have high probability of OFDI and the result after adding the control variables as well as the year and industry variables is still robust.

TABLE III IMPACT OF TOTAL FACTOR PRODUCTIVITY ON FIRMS' OUTWARD INVESTMENT DECISIONS

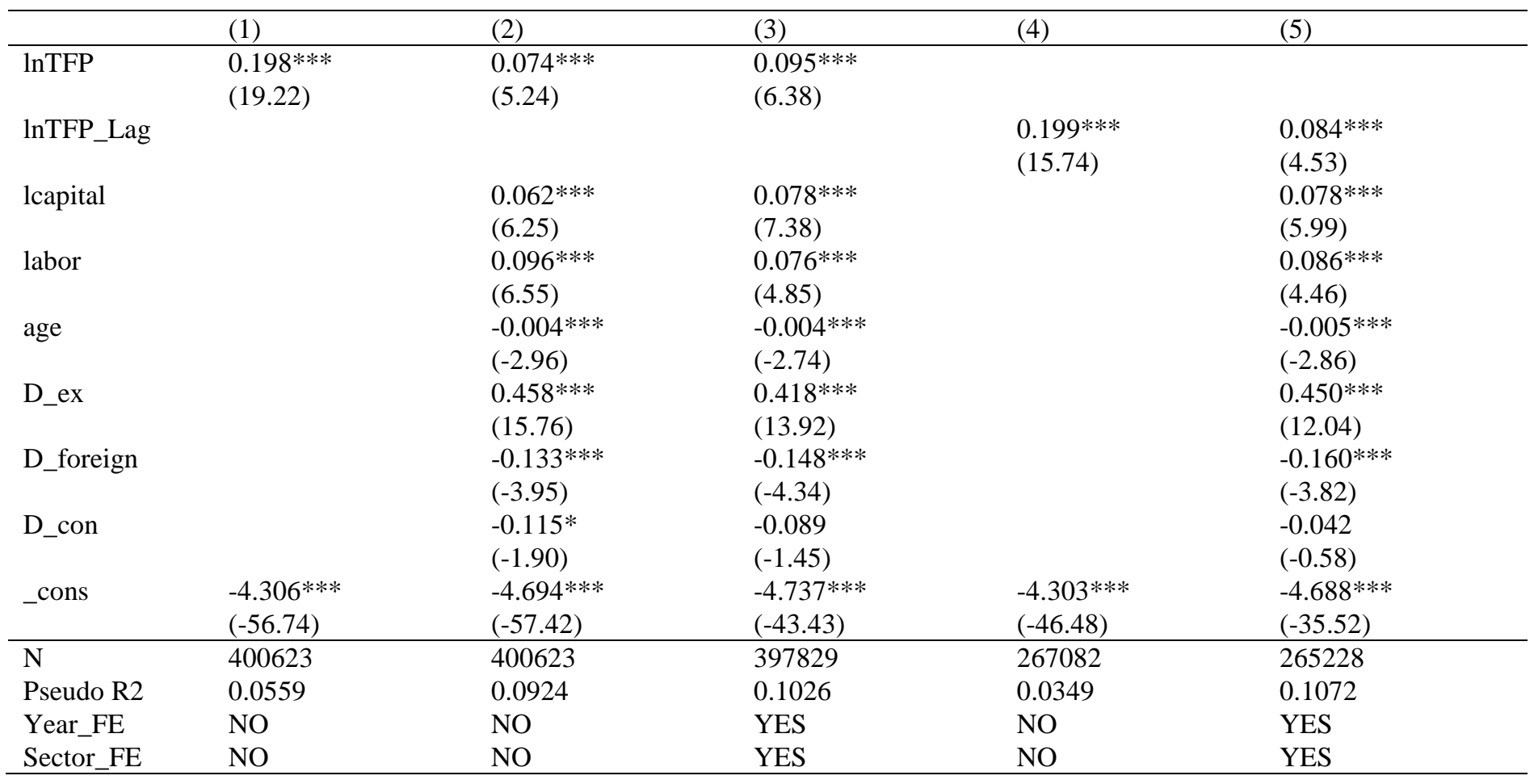

\section{CONCLUSIONS}

In recent years, the field of OFDI has attracted the attention of all sectors of the society, and the competition between China's OFDI enterprises has become increasingly fierce. It is worth mentioning that China's economic development has entered a new normal. The demographic dividend is about to disappear, and it has been very difficult for China's economy to continue to grow by relying on capital and labor input. Thus, TFP is the key source to promote economic growth and get rid of the "middle income trap". Then, how does the total factor productivity of an enterprise affect its OFDI decision? The answer to this question is both theoretical and practical. Based on the micro-level data of Chinese manufacturing companies from 2005 to 2007, the following points have been found. First, the total factor productivity of an enterprise is an influencing factor for Chinese enterprises' OFDI decisions. Second, the higher the total factor productivity, the greater the probability of OFDI.

\section{ACKNOWLEDGEMENT}

This research was financially supported by Xi'an Social Science Planning Fund Project (18J161) and China Postdoctoral Science Fund Project (2018M633446).

\section{REFERENCES}

[1] Melitz, M. J. ,The Impact of Trade on Intra-Industry Re-Allocation and Aggregate Industrial Productivity, J. Econometrica. 71.6 (2003) 1695-1725.

[2] Helpman, Elhanan, M. J. Melitz, S. R. Yeaple, Export versus FDI with Heterogeneous Firms, J. American Economic Review. 94.1 (2004) 300-316.

[3] Chen Jinghua, Industry Differences, Total Factor Productivity and Foreign Direct Investment in Service Industry: An Empirical Test Based on China's Service Industry Panel, J. World Economic Research. 9 (2015) 86-93. (In Chinese)

[4] Tian Wei, Yu Miaojie, Enterprise productivity and enterprises "going out" OFDI: An empirical study based on data at the company level, J. Economics Quarterly. 11.2 (2012) 383-408. (In Chinese)

[5] Han Jian, Productivity Threshold of Vertical and Horizontal Foreign Direct Investment - Based on the Microdata of China's Enterprise Level, J. China Economic Issues. 3 (2015) 38-50. (In Chinese)

[6] Levinsohn, James, and A. Petrin, Estimating Production Functions Using Inputs to Control for Unobservables, J. Review of Economic Studies. 70.2(2003) 317-341. 